\title{
Assessing Policy Making for ICT Innovation: A Decision Support Research Agenda
}

\author{
Ciara Fitzgerald and Frédéric Adam \\ Business Information Systems, University College Cork, Ireland \\ cfitzgeraldeucc.ie, \\ FAdam@afis.ucc.ie
}

\begin{abstract}
Our study explores European telecare policy and considers the different types of uncertainties for policy makers when addressing ICT innovation. We specifically examine 14 European countries in our study using document analysis, expert interviews and workshops. The findings reveal nuances in how policy makers are reacting to the uncertainty of telecare technologies as a representative of ICT innovation. Our contribution lies in exploring decision support as per Alter's contention that to improve the quality of decision making we most focus on broadly defined avenues for decision support rather than exclusively Decicion Support Systems [1]. Following Earl and Hopwood (1980), we analyse the case of European telecare policy and outline implications to strengthen policy making for ICT innovation [2]. Our study is pertinent to policy makers as we argue that they will increasingly be challenged to consider 'responsible innovation' in their policy making efforts.
\end{abstract}

Keywords: Decision Support, ICT Innovation, Policy Making, Responsible Innovation, Telecare Technologies.

Track: Particular domains of study in e-government and e-governance such as emergency and disaster response management, policy making, law enforcement, compliance and criminal justice.

\section{Introduction}

We are living in an innovation age challenged with increasing complexity of decisions in all aspects of society. Such ICT innovations, advancing at an unprecedented rate, demand a sophisticated policy response to assess the impact of the rapid technological advances on society. We are keen to investigate the different types of uncertainty facing policy makers in the context of ICT innovation. This study provides a wide-ranging analysis of European policy relating to telecare and telemedicine. The purpose of our study is to explore policy measures related to telecare and home-based telemedicine in the European countries/regions represented by a consortium of 14 European countries. This case is of interest as European countries are challenged with an ageing population. Between 2000 and 2050, the proportion of the world's population over 60 years will double from about $11 \%$ to 
$22 \%$. The absolute number of people aged 60 years and over is expected to increase from 605 million to 2 billion over the same period. The world will have more people who live to see their 80 s or 90 s than ever before. The number of people aged 80 years or older will have almost quadrupled to 395 million between 2000 and 2050. Indeed the probability of needing care increases with age. Less than $1 \%$ of those younger than 65 years need long-term care, while $30 \%$ of the women aged 80 years or over use long-term care services, on average across the OECD [3]. Recent innovative developments in technology have produced ICT devices supporting elderly people. Information and communication technology (ICT)-based care technologies include real-time audio and visual contacts between patients and caregivers; embedded technologies such as smart homes, clothes and furniture to monitor patients inside and even outside their homes; electronic tagging of dementia patients and more biotechnological innovations, such as implants and devices for chronic disease monitoring. These technologies cover a wide range of innovations, from those already functioning to those that are prospective and theoretical. They provide health care and enable elderly people to maintain their autonomy and allow them to live independently for a longer period of time. These technologies are subsumed under the term telecare. However as well as the positive benefits, theorists are speculating on the social and legal risks of telecare, specifically regarding the issue of technology failure and the onus of responsibility, be it users or the providers of the technology [4]. It is worth noting the intention of this paper is not to determine the ethics of telecare. Rather, this paper supports the call by Yanga and Zhiyong Lan (2010) for the need for further study to facilitate our understanding of efficient policy making for ICT innovation [5]. Given telecare technologies is a ripe area of innovation which will have positive and potentially challenging societal implications, our research objective is to explore the different types of uncertainties for policy makers addressing ICT innovation.

We situate this study against the backdrop of 'responsible innovation', a growing scholarly appreciation that the advancements in ICT should be situated within a societal context focused on the future consciousness of societal well-being. Responsible Innovation is recognised to be a dynamic concept enacted at multiple levels and is forecasted to feature on the political agenda in the coming years [6]. The term Responsible Innovation is defined as 'taking care of the future through collective stewardship of science and innovation in the present' [6 pp 3]. Our study contributes to this paradigm as it explores policy makers' response to telecare innovation and explores to what extent policy is considering the opportunities and challenges of telecare within the context of the aging society wellbeing. Within this agenda of 'Responsible Innovation', our paper will outline how decision support can facilitate better technology assessment processes, which are needed to manage innovations in ICT. The rest of the paper is organised as follows. The next section presents the literature review focusing on ICT policy making and decision support. Following this, we outline the methodology, then the findings, followed by a discussion of the findings before concluding with outlining implications for policy makers. 


\section{Literature Review}

\subsection{ICT Policy Making}

ICT policy making is a much studied area for scholars, as countries grapple with new innovative technologies and question their impact. Governments are challenged to scientifically assess societal, ethical, legal and economic aspects of technology. However, Delvenne et al (2011) argues uncertainty is no longer contained within modern structures of policy making. Specifically, they argue the current challenge for policy makers is to accommodate the uncertainty and dynamics of patterns to offer the decision- making process "a context-determined and temporally limited orientation for action that makes learning through experience possible" [7:p. 18]. Furthermore, no discussion on such complex decision making is meaningful without a discussion of the lmitations which apply to Human Decision making, as described by Simon under the term of bounded rationality [8]. Scholars argue under conditions of boundedrationality, decision makers seemingly "do what they can" or in some cases, "makedo". To further complicate matters, when contemplating boundaries in ICT policy decision making, traditional boundaries are not imposed, but constructed, bargained, negotiated and appropriated by stakeholders [7]. We speculate such boundary-less domains can result in ambiguity of decision making within a fluid environment. Policy makers need urgently to respond to demands of citizens to engage more proactively with politics in policy decisions that heavily concern particular stakeholder groups and citizens [10]. We question if policy makers as decision makers in such fluid environments are indeed 'muddling through' as per Lindblom (1959) [9]. If so, we propose a decision support lens can make a potentially powerful contribution and will provide recommendations of real pragmatic value for policy makers. Our study will address the need for more clearly defined and systematic theoretical and empirical studies to facilitate our understanding of efficient policy decisions [5].

\subsection{Decision Support}

Following Alter, one should explore how decision support can be provided when considering the feasibility of DSS. Alter $(1992,2004)$ has repeatedly pointed out that the development of DSS was secondary to the objective of improving the quality of decision making, calling for a focus on decision support rather than decision support systems [11,1]. To provide decision support, one should concentrate on developing an overall system of decision making which is based on evidence and supported by expert advice. The use of DSS in a political context can be problematic as studies found that the inherent rationality of the DSS was in conflict with how participants usually make decisions as well as with the political process [15]. We are keen to further explore the feasibility of DSS in a policy making context for ICT innovation. We argue decision making for ICT innovation policy making addresses a number of categories of uncertainty [2]. Specifically policy making for ICT innovation considers the following: 
- Uncertainty about the mechanics of technologies - the what question

- Uncertainty about their impact - the who and how questions

- Uncertainty about societal preferences - the why questions

Earl and Hopwood (1980) have theorised on the nature of uncertainty and, leveraging Thompson and Tuden (1959), they have distinguished uncertainty about the cause and effect relationship versus uncertainty which relates to the preferences of the stakeholders [2, 12]. Silver (1991) also proposes a reflection on the difference between guidance underpinned by information and guidance aimed at prescribing choices, which he respectively labels informative decisional guidance and suggestive decisional guidance [13]. In general, DSS applications must rely on the existence of clear modelling and reasoning to underpin the optimisation algorithms that are being applied. The key issue is therefore whether societal decisions in the area of ICT lend themselves to the development of what Earl and Hopwood (1980) term answer machines and what happens when the level of uncertainty and ambiguity involved means that the provision of the answer machine can potentially compromise the ability of policy makers to make the right choices. Earl and Hopwood (1980) have warned against trying to hide the true complexity of societal problems (focusing on developing DSS), rather than embracing it (focusing on improving the quality of decisions). Where assumptions are made about the future, or where consensus has not yet arisen in an organisation or society, decision support should not provide artificially complete ready-made answers and should, instead, promote judgement and dialogue amongst stakeholders. Although the concept of decisional guidance may appear intangible, Earl and Hopwood's (1980) recommendations provide tangible avenues for analysing decisional guidance in terms of its fit with the problems facing policy makers [2]. We propose therefore that certain societal problems with a given technology can lead to suggestive guidance, whereas others cannot and should not, given the state of development of policy-makers' understanding or the absence of a clear societal consensus. This has clear implications for the type of dialogue which must take place in society in relation to different types of innovations. This paper explores policy making in the area of telecare technology as an example of ICT innovation and considers how DSS can support policy making, be it as suggestive guidance or otherwise.

\section{Methodology}

The methodology utilized in this study is an in-depth case study approach. The casestudy method has been widely recommended for study areas that are not yet well understood and lack formal theories [14]. It is particularly relevant for our study as there are very few studies on the actual use of DSS in a political context [15]. It has also gained particular popularity in the public policy literature because of 'the depth and richness' the result can provide for enlightened public policies [16]. Since ICT innovation and decision support is a comparatively new and underexplored policy issue, a case study approach can provide rich context-dependent knowledge to assist 
policy-making. The fourteen countries in the European case study were Austria, Belgium, Bulgaria, The Czech Republic, Denmark, Germany, Hungary, Ireland, Lithuania, Norway, The Netherlands, Portugal, Spain and Switzerland. The selection of countries signifies the participating partners in a FP7 funded project called PACITA $^{1}$. The categories used to capture consistent data on each country, were as follows; Definitions, National Demographic Trends, National policies, Policy Enablers, Policy Enactors, Actor Involvement Incentives, Service Providers, Technologies in use, and a Risk Analysis. The choice of categories for inclusion were grounded in relation to its practical purposes as per recommended for studies analyzing and comparing ICT for Aging Society policies [17].

Specifically, we explored the definitions used in policy documents in the 14 European countries in the study. Then, we assessed demographic conditions. Next we examined specific national policies. Following this, we investigated the key actors involved. We categorized them as policy enablers and policy enactors. On consultation with national experts, there appears to be many risks but these are not recognised in policy discussions thus far. Extensive desk research was conducted for each country. To complement this, policy experts were contacted for additional information that was not easily accessible via secondary sources. The richness of information differed from each country; however this is not problematic as it reflects their differing levels of policy sophistication in the area of telecare. Therefore there are some apparent nuances in the approaches but this adds to the complexity of the findings. For the purpose of this study, relevant legal and policy documents, government publications and scholarly literature were examined, documenting developments up until September 2013. Documentary search and analysis were complemented by a series of semi-structured in-depth interviews. Finally we held a workshop with key experts to validate our results, which led to further relevant analysis as outlined in the following section.

\section{$4 \quad$ Case Study}

The primary function of telecare technology is to address the challenge of an ageing population. The societal challenges which emerged from our analysis are an increase in life expectancy, an increase in dementia and other age related illnesses, rising cost of care and increased demand for independent living solutions. Emerging technological advances in telecare and telemedicine pose new challenges for policy makers particularly with regard to uncertainty over cause and effect of the innovative technology. The findings provide a basis for commentary and serve to promote awareness of the policy status in telecare in Europe, as represented by the European countries in our study. We present the findings as per the categories of uncertainty, presented in the literature review. Specifically, we discuss uncertainty about the mechanics of technology, uncertainty about their impact and uncertainty about societal preferences.

\footnotetext{
${ }^{1}$ http: / /www.pacitaproject.eu/
} 


\subsection{Uncertainty about the Mechanics of Technologies - The What Question}

Our findings reveal common interpretations of telecare and telemedicine are used in national documents. However they are used interchangeably in many contexts. There are a number of interrelated concepts such as Ambient Assisted Living, eHealth, Assistive Technology, ICT in Health, Welfare Technology and Telehealth. This level of uncertainty is not conducive to effective policy making. There needs to be a definitive understand of what telecare technology is. Furthermore, there are differing levels of sophistication regarding telecare. Firstly, there is difference in timeline. For example 1993 was the earliest policy initiative in Austria whereby a tax funded long term care system which is independent from income was introduced. Since then, all countries in our study have documents referencing telecare, or equivalent but to varying levels of comprehensiveness. For example, the policies are at various levels of a continuum concerning frameworks for security and strategies for encouraging adoption. For example some countries are proactive in seeking opportunities for encouraging the development of telecare, whilst others are reactive and seek only to fulfil the minimum requirements of regulation. The following are areas of uncertainty about the mechanics of technologies which arose from our analysis.

- What is telecare technology?

- What are the best policies to encourage the development of telecare?

- What are the regulatory requirements?

\subsection{Uncertainty about Their Impact - The Who and How Questions}

Our findings reveal evidence of fragmented, uncoordinated decision making and implementation in the telecare domain with no central responsibility for policy making in all countries of in our study. In the category of Policy Enablers, our findings highlighted a surge in the number of government departments getting involved in the telecare domain. Due to the various groups involved we can deem telecare policy to be a complex policy making subject. To add to the complexity, there is also an additional dimension of regional versus national policy, for example in the case of Belgium. We argue there is no single group taking responsibility for the formulation of telecare policy and this can be deemed a weakness. In the category of Policy Enactors, our findings reveal there is a mix of non profit, voluntary, and nongovernmental agencies involved. Their roles are varied and include raising awareness, and dissemination of research. Similarly, we argue there is a sense of unaligned discourse in the implementation of policies relating to telecare. When researching telecare service providers, we found private firms to be dominant. There are both service and product offerings. There are a growing number of startups in this field and it is particularly common area found among spinouts from universities. A particularly interesting case is the Hagen Committee in Norway. This is a national program for municipal innovation in care where $1 \%$ of care services budget allocated to Innovation in the form of a Private public partnership. However, other countries have yet to formalize initiatives to encourage innovation between private and public 
institutions. This is an area which could be further explored. The following are areas of uncertainty about the impact which arose from our analysis.

- Who should be responsible for the formulation of telecare policy?

- Who should be responsible for the implementation of telecare policy?

- How will public- private partnerships encourage advancement of telecare technology?

\subsection{Uncertainty about Societal Preferences - The Why Questions}

Surprisingly, the societal preferences of telecare were largely absent in national telecare policy documentation. At the workshop with experts we were engaged in an interesting discussion on the risks associated with telecare. Here, a multitude of types of risks were identified including Privacy Risk, Social Risk, Technology Risk, Legal Risk and Financial Risks. The most common privacy risks were concerned with legal rights and ethical considerations not being fully addressed. The social risk of isolation was considered and the question of forced or voluntary participation was raised. The technology risk of how to secure data storage and transmission of sensitive health data were identified. Also the polarized dilemma of technology driven innovation versus user need innovation was questioned and the ramifications of this debate for policy making. Also legal risks were articulated; specifically the medical responsibility was questioned in the technology versus practitioner onus of responsibility debate in the time of malpractice. The legal risk of the lack of legislation and regulation in this space was also recognised. Finally the financial risk was discussed as to the question of who is responsible for the costs of the telecare technology. The following are areas of uncertainty about the societal preferences which arose from our analysis.

- Why are telecare risks not being discussed at policy level?

\section{$5 \quad$ Implications of Research}

As evident from our multiple country study, decision making regarding telecare policy is a fragmented, challenged process, with differing levels of sophistication. Our interest lies in decision support as a provision to holistic policy making in telecare to address the grand challenge of ageing. We argue policy makers, when challenged with policy making in ICT innovation are suffering from a crisis of legitimacy as evident from the different types of uncertainty. As articulated by Kovisto et al 2009, innovation processes have shifted from 'the positivist and rationalist technologyfocused approaches towards the recognition of broader concerns that encompass the entire innovation system, including its economic, social and economic perspectives' [18: p1164).

As there are nuances among countries in their policy efforts, we argue decision support can frame the uncertainty over preferences and reduce uncertainty over cause 
and effect. Carter and Bélanger (2005) argue government agencies must understand the factors that influence citizen adoption of innovation [19]. Their findings indicate that perceived ease of use, compatibility and trustworthiness are significant predictors of citizens' intention to adopt technology. Similarly, other studies highlight trust as the key success factor in technology acceptance of multi criteria decision support systems in the case of high impact decisions [20]. We advance this argument and argue decision support can help promote judgment and dialogue with citizens thus providing rich material. In support of our argument, Rose and Grant (2010) argue that involvement from all stakeholders, including citizens of various ICT means and capabilities is a requisite for successful implementation [21].

We propose a research agenda to explore further decision support mechanisms to support ICT policy making for an Aging Society. We propose a number of implications are to be considered as evident from the findings of our case study of European telecare policy. As shown in our case study, none of the 14 countries have a dedicated policy for telecare. Whilst all recognize their national demographic trends demand a telecare response, there are a wide variety of responses in how the countries in our study are engaging with telecare. A decision support response can frame the uncertainty and present suggestive decisional guidance as per Earl and Hopwood (1980) recommendation, thus instilling trust and legitimacy in the policy making process [2]. Our findings recognize the challenge of applying a DSS to a decision in complicated and contested matters such as the use of technology in the aging society yet we support a DSS offering of suggestive guidance with the following two caveats. Firstly, policy- makers need to understand the clear societal consensus [2], and secondly, where assumptions are made about the future, or where consensus has not yet arisen in an organisation or society, decision support should not provide artificially complete ready-made answers and should, instead, promote judgement and dialogue amongst stakeholders [2].

Furthermore, decision support can increase integrity and honesty in policy decisions, two vital components to the success of transformation of policy making in technology. Public sector values are the foundation from which the idea of genuine transformation ultimately derives [22]. The second implication of a decision support framework will promote a sense of action thus ensuring a sense of positivity about ICT policy decision making. The final implication will translate a respect for the citizen. Decision support for policy making in ICT innovation will support moving beyond a utilitarian and unidirectional approach to technology, thus foster engagement through institutionalization of citizen engagement and debate on contentious issues in ICT through increased transparency in the outcomes of decisions [23].

\section{Concluding Comments}

The paper will be of interest to IS scholars, policy makers, and society in general as we explore decision support to enhance ICT policy making. Specifically, our study provides a picture of the uncertainty in policy making relating to ICT innovation, and 
lends itself to further study of how decision support can frame uncertainty. We have considered 14 countries and their policy approaches to telecare. We suggest that contemplating decision support will frame uncertainty and deliver a number of implications, including legitimacy of policy, infer a sense of action and deliver a respect for the citizen. Our framework supports the feasibility and desirability of shaping and steering decision support in ICT innovation policy making.

\section{References}

[1] Alter, S.: A work system view of DSS in its 4th decade. Decision Support Systems 38(3), 319-327 (2004)

[2] Earl, M.J., Hopwood, A.G.: From management information to information management. In: Lucas, Land, Lincoln, Supper (eds.) The Information Systems Environment. IFIP, pp. 133-143. North-Holland (1980)

[3] OECD, Live Longer, Work Longer. OECD. Paris (2011)

[4] Percival, Hanson: Big brother or brave new world? Telecare and its implications for older people's independence and social inclusion. Critical Social Policy 26(4), 888-909 (2006)

[5] Yanga, L., Zhiyong Lan, G.: Internet's impact on expert-citizen interactions in public policymaking-A meta analysis. Government Information Quarterly 27(4), 431-441 (2010)

[6] Stilgoe, J., Owen, R., Macnaghten, P.: Developing a framework for responsible innovation. Research Policy (2013)

[7] Delvenne, P., Fallon, C., Brunet, S.: Parliamentary technology assessment institutions as indications of reflexive modernization. Technology in Society 33(1-2), 36-43 (2011)

[8] March, J., Simon, H.: Organisations. J. Wiley, New York (1958)

[9] Lindblom, C.: The science of 'muddling through'. Public Administration Review, 779788 (1959)

[10] Wimmer, M., Scherer, S., Moss, S., Bicking, M.: Method and Tools to Support Stakeholder Engagement in Policy Development: The OCOPOMO Project. International Journal of Electronic Government Research 8(3), 98 (2012)

[11] Alter, S.: Why persist with DSS when the real issue is improving decision making? In: Jelassi (ed.) Decision Support Systems: Experiences and Expectations. North Holland (1992)

[12] Thompson, J.D., Tuden, A.: Strategies, structures, and processes of organizational decision. Bobbs-Merrill (1967)

[13] Silver, M.S.: Decisional guidance for computer-based decision support. MIS Quarterly 15(1), 105-122 (1991)

[14] Yin, R.K.: Case study research: Design and methods, vol. 5. Sage (2009)

[15] Andersson, A., Gronlund, A., Astrom, J.: You can't make this a science- Analysing decision support systems in political contexts. Government Information Quarterly 29(4), 543-552 (2012)

[16] Silverman, D.: Doing qualitative research: A practical handbook. SAGE Publications Limited (2013)

[17] Ishmatova, D., Thi Thanh Hai, N.: Towards a framework for analysing and comparing ICT policies for Aging Society Policies: A First Approximation. In: ICEGOV 2013, Seoul, Republic of Korea, October 22-25 (2013) 
[18] Koivisto, R., Wessberg, N., Eerola, T., Kivisaari, S., Myllyoja, J., Halonen, M.: Integrating future-oriented technology analysis and risk assessment methodologies. Technological Forecasting and Social Change 76, 1163-1176 (2009)

[19] Carter, L., Bélanger, F.: The utilization of E-Government services: Citizen trust, innovation and acceptance factors. Information Systems Journal 15(1), 5-25 (2005)

[20] Maida, M., Maier, K., Obwegeser, N., Stix, V.: Success of multi criteria decision support systems: The relevance of Trust. In: 46th Hawaii International Conference on System Systems, pp. 1530-1605 (2013)

[21] Rose, Grant: Critical Issues pertaining to the planning\& implementation of e-government initiatives. Government Information Quarterly 27(1), 26-33 (2010)

[22] Bannister, F., Connolly, R.: ICT, public values and transformative government: A framework and programme for research. Government Information Quarterly (2014) (forthcoming)

[23] Evans, A.M., Campos, A.: Open Government Initiatives: Challenges of Citizen Participation. Journal of Policy Analysis and Management 32, 172-185 (2013) 